\title{
Paita en una tradición de Ricardo Palma
}

\author{
Marco Martos Carrera \\ Academia Peruana de la Lengua \\ marcomartos9@hotmail.com
}

\section{Resumen}

Aunque preferentemente limeñas, las tradiciones de Ricardo Palma abarcan buena parte del territorio nacional. La ponencia se detiene en analizar aquella en la que aparece Manuelita Sáenz en su edad provecta, en el puerto de Paita. El trabajo se complementa con referencias a un libro reciente La Nantuca de Maintope de Miguel Cortés, un autor piurano.

Palabras clave: Palma, Paita, Manuelita Sáenz, Cortés.

\begin{abstract}
Although preferably in Lima, the traditions of Ricardo Palma cover a large part of the national territory. The paper focuses on analyzing the one in which Manuelita Sáenz appears in his provecta age, in the port of Paita. The work is complemented by references to a recent book La Nantuca de Maintope by Miguel Cortés, a Piuran author.
\end{abstract}

Keywords: Palma, Paita, Manuelita Sáenz, Cortés 


\section{Marco Martos Carrera}

Escritor, poeta y periodista. Uno de los representantes de la Generación del 60 en la poesía peruana. Ex presidente de la Academia Peruana de la Lengua. Catedrático de la Universidad Nacional Mayor de San Marcos y ex decano de la Facultad de Letras y Ciencias Humanas de dicha casa de estudios. 
Los amantes de la literatura del Perú debemos agradecimiento a la Universidad Ricardo Palma y al Instituto Ricardo Palma por la sostenida labor a favor de la difusión de la obra monumental del tradicionista. Cierto es que el nombre del ilustre escritor, nimbado de la gloria literaria, es conocido en todos los rincones del país merced al hecho de que aparece en los programas escolares, pero es verdad también que ese esfuerzo literario es insuficiente para que tan magnífica obra cale en el espíritu de todos los peruanos y llegue allende de nuestras fronteras. Por eso, cada año, los coloquios sobre la obra de nuestro escritor son recibidos con expectativa por el mundillo literario y por los lectores que luego leen las ponencias presentadas. Sin embargo, justo es decir que cada vez es más difícil encontrar algún tema o asunto que no haya sido trabajado por algún estudioso. En apariencia por lo menos, los investigadores no han dejado página de Palma sin escudriñar y es muy complicado intentar ser original en los estudios. Palma, también por esa razón, es un desafío.

Me hallaba leyendo un libro sobre Paita, de un autor piurano, Miguel Cortés, de título enigmático La Nantuca de Maintope en el instante en el que sonó el teléfono, al otro lado de la línea, un colega del Instituto Ricardo Palma, Carlos Pérez, con amable insistencia, reclamaba mi participación en las jornadas en homenaje a Ricardo Palma, que es, sin duda, uno de mis escritores favoritos, junto al Inca Garcilaso y a César Vallejo. Tomado de sorpresa, en esa circunstancia, no atiné a negarme, lo que hubiera sido lo pertinente, dada la cantidad de compromisos literarios que asumo, a veces más allá de mis menguadas fuerzas, sino que acepté, verdad que titubeando. Conminado a decir el título de mi ponencia, por una asociación de ideas con el libro que estaba leyendo, con Manuelita Sáenz y seguramente con el propio puerto de Paita que iluminó los días de mi infancia, solo dije "Paita en una tradición de Ricardo 
Palma". Grande ha sido mi sorpresa al ver que Miguel Cortés abre su sorprendente libro con una cita de Palma que me llevó directo a la tradición aparecida en la sétima entrega de esos escritos, que con dificultad pude hallar en la edición monumental de la obra de Palma hecha por la editorial Aguilar. ${ }^{1}$ El escrito, titulado originalmente" La protectora y la libertadora, "alude a las damas favoritas de José de San Martín, Rosa Campusano, y de Simón Bolívar, Manuelita Sáenz. Tate, me dije, aquí está la punta del hilo de la madeja y me eché a leer Palma; en la parte pertinente a la Sáenz, empieza así:

\section{I- Doña Manuela Sáenz}

El puerto de Paita por los años de 1856, en que era yo contador a bordo de la corbeta de guerra Loa, no era, con toda la mansedumbre de su bahía y excelentes condiciones sanitarias, muy halagüeña estación naval para los oficiales de marina. La sociedad de familias con quienes relacionarse decorosamente era reducidísima. En cambio, para el burdo marinero, Paita con su barrio de Maintope, habitado una puerta sí y otra también por proveedoras de hospitalidad (barata por el momento, pero carísima después por las consecuencias), era otro paraíso de Mahoma, complementado con los nauseabundos guisotes de la fonda o cocinería de don José Chepito, personaje de inmortal renombre en Paita.

De mí sé decir que rara vez desembarcaba, prefiriendo permanecer a bordo entretenido con un libro o con la charla jovial de mis camaradas de nave.

l La tradición aparece en la edición de Aguilar entre las páginas 1132 y 1135. Alberto Varillas me hace saber, en una comunicación escrita, que apareció por primera vez en el texto de Ricardo Palma Ropa vieja, de 1899, con el título de La protectora y la libertadora. Aparece luego en varios números de El Perú ilustrado. 
Una tarde, en unión de un joven francés dependiente de comercio, paseaba por calles que eran verdaderos arenales. Mi compañero se detuvo a inmediaciones de la iglesia, y me dijo:

- ¿Quiere usted, don Ricardo, conocer lo mejorcito que hay en Paita? Me encargo de presentarlo, y le aseguro que será bien recibido.

Ocurrióme que se trataba de hacerme conocer alguna linda muchacha; y como a los veintitrés años el alma es retozona y el cuerpo pide jarana, contesté sin vacilar:

-A lo que estamos, benedicamos, franchute. Andar y no tropezar.

-Pues en route, mon cher.

La visión del puerto de Paita que ofrece Ricardo Palma y que alude a 1856, no es muy halagüeña. En la entrelínea podemos colegir que nuestro escritor era muy selectivo en sus amistades, que apenas bajaba de su embarcación; prefería, en suma, permanecer entre los suyos, que alternar con la población. Eran los marineros, los que sin ningún escrúpulo, se mezclaban con los lugareños. Y a dónde iban los marineros, al barrio del placer, que se llamaba precisamente "Maintope". De adolescente leí la tradición y nunca supe acertar con la razón de tal nombre. Ahora tenía la oportunidad, y me la daba Miguel Cortés con su libro, quien escribe:

- iHey Charly, caman letsgo to di Mantuca in Maintope estrit to foque foque uit biutiful señoritas.

La parrafada en un inglés vaporino, paporreteado y mascado, con la que el churre recibía a los viajeros que saltaban, uno a uno, del bote que acababa de trasladarlos a la playa, desde 
el fondeadero en que había echado anclas por la mañana el "Nauty", barco mercante y de pasajeros, su base San Francisco de California, hizo sonreír a Charly Parker, un joven alto, rubio y barbado quien, descalzo, con el pantalón remangado hasta las rodillas y los zapatos colgados al hombro, trataba de poner pie en tierra sin mojar el equipaje que cargaba en las manos. La proverbial mansedumbre del mar de Paita que besaba la playa sin levantar las olas, le facilitó la maniobra.

- ¿Cómo sabes tú mi nombre? Preguntó sorprendido Charles, acariciando el pelo hirsuto del chiquillo palomilla.

- Acá a todo americano caballero le decimos Charlie, explicó el churre, sorprendido a su vez de que este Charlie se expresara en fluido castellano....

La relevancia de Paita en aquella época consistía en ser la puerta de entrada al fabuloso reino del Perú. Aquí desembarcaban los viajeros provenientes de España, vía Panamá, incluyendo virreyes y demás dignatarios, para continuar por tierra su viaje a Lima, a lomo de mula, evitando así la insufrible e interminable navegación hacia el Callao, que solía durar no menos de dos meses, y con frecuencia, mucho más, dependiendo de los caprichos de la madre naturaleza que gobierna a los vientos y que en este tramo de la costa obligaba a una lentísima navegación con viento en contra.

Pero en los albores de la República, ingleses y norteamericanos escogieron Paita como puerto de aprovisionamiento de sus flotas balleneras que venían a estas lejanas aguas del Pacífico en pos del codiciado aceite de esperma de cachalote, que iluminaba las ciudades de Europa y que de pronto lo convirtieron en un activo y floreciente centro proveedor de servicios para los barcos y sus tripulantes. 
A lo largo y ancho de la playa se instalaron astilleros y tiendas de aparejos marítimos para atender las necesidades de los navíos; y las calles aledañas a la plaza mayor se llenaron de comercios de todo tipo. En las callejas alejadas del centro proliferaron pulperías, fondas, cantinas, billares, garitos y burdeles, para satisfacer a las tripulaciones de los barcos balleneros que desembarcaban ávidas de diversión y con dinero bastante para despilfarrar. (Cortés, 2012: 15)

Hablando de los marineros que llegaban a Paita en el siglo XIX, escribe Miguel Cortés:

También se les encontraba sentados en las bancas de la Plaza de Armas, saboreando toda clase de frutas de la estación: mangos, ciruelas, guayabas, chirimoyas, sandías, papayas, charlando animadamente, fumando pipas o cantando en coro, acompañándose por la música de sus armónicas. No faltaban aquellos que a gritos se citaban con los conocidos de otros barcos para encontrarse más tarde en el bar la "Nantuca" en Maintope a tomarse unas copas. (Cortes, 2012: 37)

Lo de "Nantuca" no tenía que ver con Antuca, como señala el sentido común, sino con Nantucket, lugar del que eran oriundos muchos marineros que llegaban a Paita en los barcos balleneros. La gente comenzó a llamar al burdel "La Nantuca" como natural derivación de Nantucket. Y junto al prostíbulo empezaron a aparecer pulperías, cantinas, billares, garitos de juego. Toda esta corte de los milagros quedaba en la última calle, pegada al cerro, que se conocía como "callecita sin nombre" hasta que los marineros norteamericanos la bautizaron como "Maintop", voz marinera que en el idioma inglés significa "cofia del palo mayor" y que derivó a "Maintope" en el castellano del norte del Perú, que es la palabreja que emplea Palma con mucho 
conocimiento de causa, como se ve por los párrafos que hemos citado supra.

La estrategia de Palma a lo largo de la narración es contrastar esta imagen del placer marinero, este ambiente prostibulario, con otro sosegado, de antiguas glorias:

Avanzamos media cuadra de camino, y mi cicerone se detuvo a la puerta de una casita de humilde apariencia. Los muebles de la sala no desdecían en pobreza. Un ancho sillón de cuero con rodaje y manizuela, y vecino a éste un escaño de roble con cojines forrados en lienzo; gran mesa cuadrada, en el centro; una docena de silletas de estera, de las que algunas pedían inmediato reemplazo; en un extremo, tosco armario con platos y útiles de comedor, y en el opuesto una cómoda hamaca de Guayaquil.

En el sillón de ruedas, y con la majestad de una reina sobre su trono, estaba una anciana que me pareció representar sesenta años a lo sumo. Vestía pobremente, pero con aseo; y bien se adivinaba que ese cuerpo había usado, en mejores tiempos, gro, raso y terciopelo.

Era una señora abundante de carnes, ojos negros y animadísimos en los que parecía reconcentrado el resto de fuego vital que aún la quedara, cara redonda y mano aristocrática.

-Mi señora doña Manuela -dijo mi acompañante-, presento a usted este joven, marino y poeta, porque sé que tendrá usted gusto en hablar con él de versos.

-Sea usted, señor poeta, bienvenido a esta su pobre casa, contestó la anciana, dirigiéndose a mí con un tono tal de 
distinción que me hizo presentir a la dama que había vivido en alta esfera social.

Y con ademán lleno de cortesana naturalidad, me brindó asiento.

Nuestra conversación, en esa tarde, fue estrictamente ceremoniosa. En el acento de la señora había algo de la mujer superior acostumbrada al mando y a hacer imperar su voluntad. Era un perfecto tipo de la mujer altiva. Su palabra era fácil, correcta y nada presuntuosa, dominando en ella la ironía.

Desde aquella tarde encontré en Paita un atractivo, y nunca fui a tierra sin pasar una horita de sabrosa plática con doña Manuela Sáenz. Recuerdo también que casi siempre me agasajaba con dulces hechos por ella misma en un braserito de hierro que hacía colocar cerca del sillón.

La pobre señora hacía muchos años que se encontraba tullida. Una fiel criada la vestía y desnudaba, la sentaba en el sillón de ruedas y la conducía a la salita.

Cuando yo llevaba la conversación al terreno de las reminiscencias históricas; cuando pretendía obtener de doña Manuela confidencias sobre Bolívar y Sucre, San Martín y Monteagudo, u otros personajes a quienes ella había conocido y tratado con llaneza, rehuía hábilmente la respuesta. No eran de su agrado las miradas retrospectivas, y aun sospecho que obedecía a calculado propósito el evitar toda charla sobre el pasado.

Esbocemos ahora la biografía de nuestra amiga. 
Doña Manuela Sáenz, perteneciente a familia de holgada posición, nació en Quito, en las postrimerías del pasado siglo, y se educó en un convento de monjas de su ciudad natal. Era, en dos o tres años, mayor que su compatriota la guayaquileña Campusano. En 1817, contrajo matrimonio con don Jaime Thorne, médico inglés que pocos años más tarde vino a residir en Lima, acompañado de su esposa.

No podré precisar la fecha en que rota la armonía del matrimonio, por motivos que no me he empeñado en averiguar, regresó doña Manuela a Quito; pero debió ser a fines de 1822; pues entre las ciento doce caballeresas de la Orden del Sol, figura la señora Sáenz de Thorne, que indudablemente fue una de las más exaltadas patriotas.

Después de la victoria de Pichincha, alcanzada por Sucre en mayo del 22, llegó el Libertador a Quito, y en esa época principiaron sus relaciones amorosas con la bella Manuelita, única mujer que, después de poseída, logró ejercer imperio sobre el sensual y voluble Bolívar.

Durante el primer año de permanencia del Libertador en el Perú, la Sáenz quedó en el Ecuador entregada por completo a la política. Fue entonces cuando lanza en ristre y a la cabeza de un escuadrón de caballería sofocó un motín en la plaza y calles de Quito.

Poco antes de la batalla de Ayacucho se reunió doña Manuela con el Libertador, que se encontraba en Huaura.

Todos los generales del ejército, sin excluir a Sucre, y los hombres más prominentes de la época, tributaban a la Sáenz las mismas atenciones que habrían acordado a la esposa legítima del Libertador. Las señoras únicamente eran esquivas para con la favorita; y ésta, por su parte, nada hacía 
para conquistarse simpática benevolencia entre los seres de su sexo.

Al regresar Bolívar a Colombia, quedó en Lima doña Manuela; pero cuando estalló en la división colombiana la revolución encabezada por Bustamante contra la Vitalicia de Bolívar, revolución que halló eco en el Perú entero, la Sáenz penetró, disfrazada de hombre, en uno de los cuarteles, con el propósito de reaccionar un batallón. Frustrado su intento, el nuevo gobierno la intimó que se alejase del país, y doña Manuela se puso en viaje hasta juntarse con Bolívar en Bogotá. Allí Bolívar y su favorita llevaron vida íntima, vida enteramente conyugal; y la sociedad bogotana tuvo que hacerse de la vista gorda ante tamaño escándalo. La dama quiteña habitaba en el palacio de gobierno con su amante.

La Providencia reservaba a la Sáenz el papel de salvadora de la vida del Libertador; pues la noche en que los septembristas invadieron el palacio, doña Manuela obligó a Bolívar a descolgarse por un balcón, y viéndolo ya salvo en la calle, se encaró con los asesinos, deteniéndolos y extraviándolos en sus pesquisas para ganar tiempo y que su amante se alejase del lugar del conflicto. (Palma, 1964: 113)

Corazón altamente generoso, obtuvo doña Manuela que Bolívar conmutase en destierro la pena de muerte que el Consejo de guerra había impuesto, entre otros de los revolucionarios, a dos que fueron los que más ultrajes la prodigaron. Bolívar se resistía a complacerla; pero su amada insistió enérgicamente y dos existencias fueron perdonadas. iNunca una favorita pudo emplear mejor su influencia para practicar acción más noble!

Muchos años después de la muerte de Bolívar, acaecida en diciembre de 1830, el Congreso del Perú (y entiendo que también uno de los tres gobiernos de la antigua Colombia) 
asignó pensión vitalicia a la Libertadora, apodo con que, hasta en la historia contemporánea, es conocida doña Manuela. Algo más. En su vejez no se ofendía de que así la llamasen, y en diversas ocasiones vi llegar a su casa personas que, como quien hace la más natural y sencilla de las preguntas, dijeron: «iVive aquí la Libertadora?». Doña Manuela sonreía ligeramente y contestaba: «Pase usted. ¿Qué quiere con la Libertadora?».

¿Qué motivos tuvo la amada de Bolívar para venir a establecerse y a morir en uno de los por entonces más tristes lugarejos del Perú? La pobre baldada me dijo, un día en que aventuré la pregunta, que había elegido Paita por consejo de un médico, quien juzgaba que con baños de arena recobrarían los nervios de la enferma la flexibilidad perdida. Alguien ha escrito que por orgullo no quiso doña Manuela volver a habitar en las grandes ciudades, donde había sido admirada como astro esplendoroso: temía exponerse a vengativos desdenes. ${ }^{2}$

Queda claro, a la luz de los textos que la alusión al barrio de Maintope en la Paita de 1856 no es un azar, ayuda a contextualizar toda la narración. Ricardo Palma, con su prosa zumbona y divertida no suele detenerse en parrafadas moralistas, pero en la entrelínea de su texto asoma la clase de liberal que era. Pareciera que en el fondo, la dama tullida que conoció en 1856 en el puerto de Paita, merecía sus íntimos reproches; la mujer aventurera que había ayudado en momentos de peligro al libertador, que había abandonado al marido para seguir la suerte del héroe, muerto éste, ganaba, tal vez, en la pluma de Palma, ese castigo: vivir en uno de los más tristes lugarejos del Perú. Felizmente el tradicionista no es fuente absoluta de la verdad. Miguel Grau, nuestro héroe ejemplar, pasó con felicidad parte

2 Ibidem. p. 1134. 
de su infancia en Paita y lo más recordable de ella no son los lupanares, ni la figura austera y tullida de Manuelita Sáenz. Es la belleza natural, del mar y la bahía, una de las más hermosas de la tierra.

\section{Bibliografía}

Palma, R. (1964). Tradiciones peruanas completas. Madrid: Aguilar.

Palma, R. (1996). Tradiciones peruanas. París: Colección Archivos.

Cortés, M. (2012). La Nantuca de Maintope. Lima: Independiente.

Recibido: 24 de septiembre 2016

Aprobado: 15 de noviembre 2016 